\title{
DEVELOPMENT OF A SINKHOLE RAVELING CHART BASED ON CONE PENETRATION TEST (CPT) DATA
}

\author{
Ryan Shamet \\ Department of Civil, Environmental, and Construction Engineering University of Central Florida, 4000 Central \\ Florida Blvd, Orlando, FL, 32816, Rshamet@knights.ucf.edu
}

Boo Hyun Nam

Department of Civil, Environmental, and Construction Engineering University of Central Florida, 4000 Central

Florida Blvd, Orlando, FL, 32816, Boohyun.nam@ucf.edu (corresponding)

\section{David Horhota}

State Materials Office, Florida Department of Transportation, 5007 N.E. 39th Avenue, Gainesville, FL 32609,

David.Horhota@dot.state.fl.us

\begin{abstract}
Naturally occurring sinkholes in Florida are formed when the soluble limestone bedrock weathers and creates cavities at its interface with the overburden finergrained soils. The overburden soil then erodes into the limestone fissures, thus weakening the strength and holding capacity of the soil above. This initial stage of a sinkhole is referred to as soil raveling and is considered to be the most effective time to perform soil improvements measures, such as grouting, to mitigate further expansion of the subterranean void. Geotechnical engineers and scientists use subsurface exploration techniques such as Cone Penetration Testing (CPT) to stratify soils and estimate soil properties. This paper presents a CPT-based raveling chart, to be used in identifying raveled soils in Central Florida during initial subsurface exploration. The raveling-chart was developed by collecting a large sample of CPT data (i.e cone tip resistance, $\mathrm{q}_{\mathrm{c}}$, and sleeve frictional resistance, $\mathrm{f}_{\mathrm{s}}$ ) from multiple sites within the same geological formation. CPT data was grouped within three categories: collapsed sinkholes, suspected raveling, and noln-raveled, and plotted using a scatter of data points with coordinates $\left(\mathrm{f}_{\mathrm{s}}, \mathrm{Q}_{\mathrm{tn}}\right)$; that is sleeve friction resistance, and normalized tip resistance. A simple statistical analysis was applied for the resulting data group to create envelopes, or threshold lines, which bound the data to create certain categories. The resulting chart provides quantifiable measure of sinkhole raveling due to soil erosion.
\end{abstract}

\section{Introduction}

Sinkhole risk assessment is not a simple task, and effective prediction of such events would require an extensive amount of knowledge and research in multidisciplinary subjects. Sinkholes in Central Florida are caused by soil instability, geological formation and degradation, and hydrological extreme events. Studies have shown sinkholes are more frequent in the rainy months following a severe drought (Tihansky, 1999), but can also occur sporadically due to human-induced influences such as over-pumping of the Floridan aquifer for extended periods of time. Other human-induced sinkhole-phenomenon found in Central Florida cities, include poorly constructed storm water pipes which may leak or break and over time erode the soil underneath, causing collapse above. These "wash-out" cases of sinkhole involve a similar internal erosion mechanism.

Naturally occurring sinkholes are a function of soluble bedrock, groundwater flow characteristics, and soil type. Over geologic time, finer-grained soils dislodge at the bedrock interface, and erode into the cavities within limestone. In areas where there is a positive difference between the non-artesian groundwater level and the piezometric level of the Floridan aquifer, a hydraulic gradient can expedite the internal erosion in concentrated areas through seepage forces and subsequent piping (Sinclair, 1986). Figure 1 presents the conceptual progression and profiles of the most typical type of naturally occurring sinkhole in central Florida: the cover collapse. This form of sinkhole only develops in certain types of geology where there exist some strata with relatively high cohesive properties overlain by sandy material. Internal erosion within this competent clay or silt layer, enables formation of a void as the finer-grained soil migrates into the cavities of the limestone. This zone of internally eroded soil is known as soil raveling.

From a civil engineering perspective, initial detection of this raveled soil zone is key to maximize effectiveness of any required sinkhole mitigation procedures (e.g. grouting), and to minimize the risk of constructioninduced collapse (e.g. groundwater pumping, pile driving, or increase in stress from heavy machinery). However, detection practices of raveled soils are not well defined and are far from being standardized. The objective of this paper is to present a technique to detect 


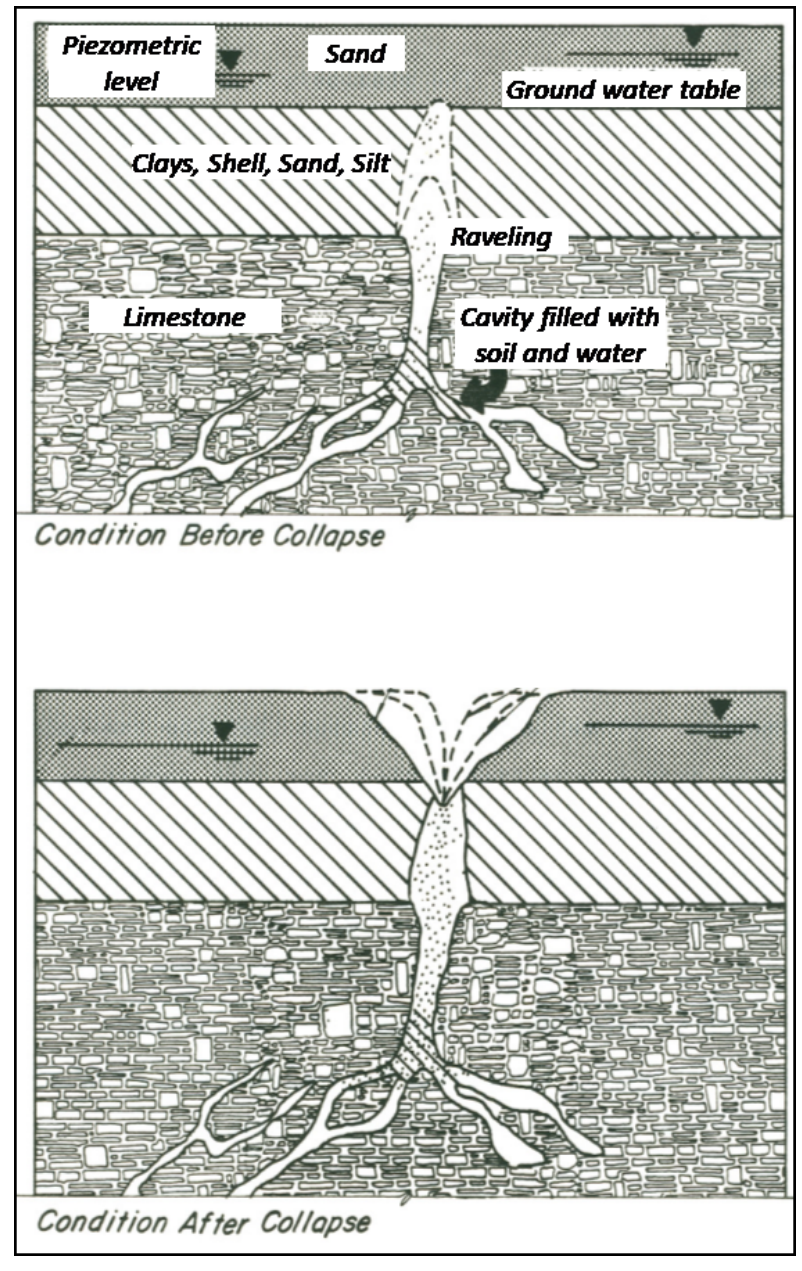

Figure 1. Conceptual Profile of Sinkhole formation and raveling phenomenon. (from Jammal, 1984)

these raveled zones using Cone Penetration Test (CPT), which is a common subsurface test during initial site investigation.

\section{Cone Penetration Testing}

The Cone Penetration Test (CPT) was developed from the need to quickly estimate the strength of subsurface soils without the use of large scale, intrusive drilling equipment. The test consists of a hydraulic ram (commonly mounted on an off-road vehicle) which pushes a probe and subsequent series of harden steel rods into the ground at a constant rate $(2 \mathrm{~cm} / \mathrm{s})$. The probe (shown in Figure 2) has a conical point with apex angle of $60^{\circ}$. Electric transducers within the probe measure the reaction forces behind the cone tip and along a $14 \mathrm{~cm}$ long section of the outer pipe diameter, resulting in measurements of cone tip resistance $\left(\mathrm{q}_{\mathrm{c}}\right)$ and sleeve frictional resistance $\left(f_{s}\right)$, respectively. Recently produced probes also allow for the measurement of pore-water pressure with depth, through piezo-

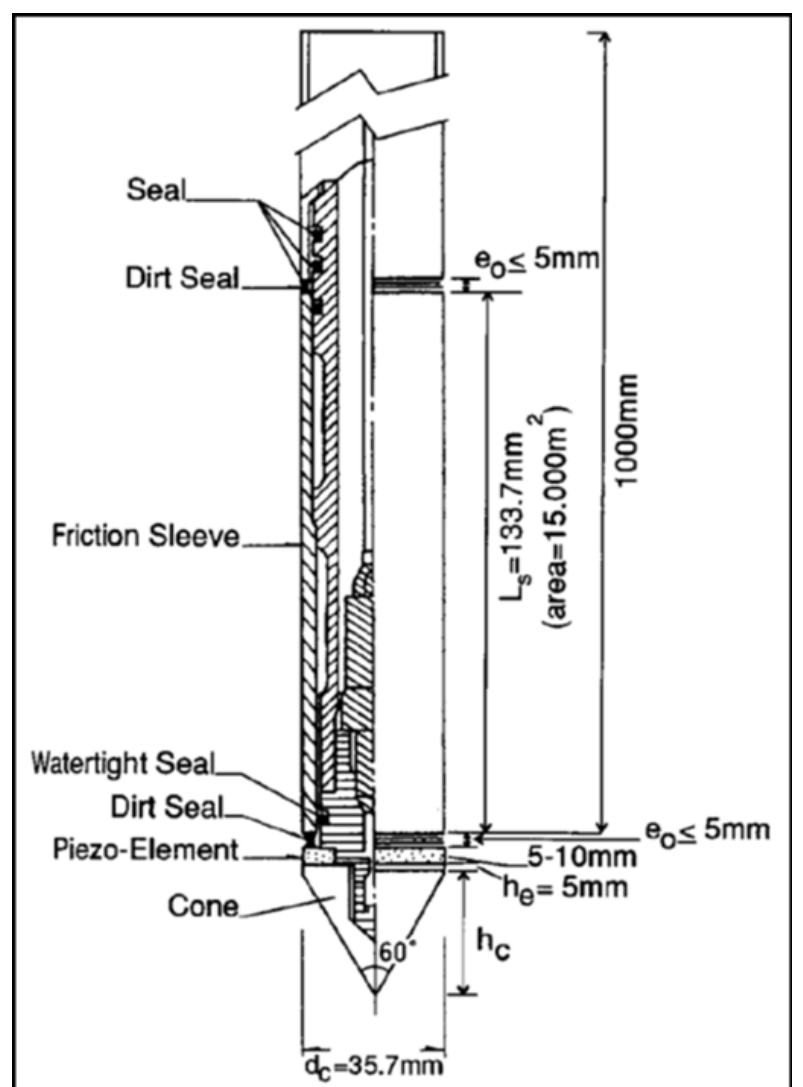

Figure 2. Schematic section through a CPTU probe (from ASTM D 5778-95)

element transducers. The major benefit of CPTs over the conventional Standard Penetration Test (SPT) is its ability to detect discrete changes in soil density, and to provide a continuous profile of stiffness data during penetration. This benefit makes the CPT ideal for detecting and analyzing anomalous soils which may be indicative of geohazards such as sinkholes or landslide slip-planes. Unfortunately, the CPT does not provide any insitu soil samples like the SPT, therefore subsurface characterization using strictly CPTs is not advised without a good understanding of expected soil types at a project site. The CPT data analyzed in this study was obtained from test sites with available SPT and soil classification data used for verification.

\section{Methodology}

CPT provides engineers and geologists an immense amount of data regarding the soil stiffness profiles with depth. The conventional CPT provides a data set consisting of tip resistance, $q_{c}$, and sleeve friction $f_{s}$, every $2 \mathrm{~cm}$ of penetration. Development of correlations to estimate soil classification, soil strength parameters, and soil capacity limits, is a well-established research area (Meyerhof, 1956; Schmertmann, 1978; Robertson, 
1990). However, very little in-depth research has been performed to link CPT results with sinkhole-prone soils. Data collection, filtering, and analyzing was held in high regards in this study to ensure an accurate raveling criteria useful for Central Florida practitioners. With hopes to understand and identify trends in how CPTs record measurements in raveled soils, subsurface data was collected from several known sinkhole active sites in central Florida, exhibiting karst terrain. To account for any variation in soil type (even on a local scale), the data processed in this study was collected within the same geological formation in Central Florida and shared similar characteristics with encountered stratigraphy.

\section{Data collection and preparation}

CPT data was provided for this study by Florida Department of Transportation (FDOT) District 5. Their available database of Cone Penetration testing performed at active sinkhole project sites consisted of a large amount of subsurface data performed to mitigate or repair natural-sinkholes occurring under or near central Florida's highway within the past 15 years. From this data pool, a total of 4 sites were chosen for this study, due to their similarities in encountered strata, elevations, and hydrogeological conditions. All four sites also lay within the same geological formation, as shown in Figure 3. The Cypresshead Formation (Tc) is found only in the Florida peninsula and eastern parts of Georgia.
This formation originates from the upper Pliocene epoch ( $\sim 5.3$ to 2.5 million years before present) and consists of reddish brown unconsolidated to poorly consolidated, fine clean to clayey sands (FGS, 2001). At these central Florida test sites, the Cypress head formation is underlain by a relatively thin layer of Hawthorne groups of soils (Th and Thc) which are then underlain by the Ocala limestone bedrock (To). The Hawthorne Group consists primarily of marine deposited clayey to silty sands with trace phosphate mineral and shell. This layer generally acts as the confining unit in this area, separating the surficial aquifer and the upper Floridan aquifer.

The CPT data was first collected and categorized based on its original purpose of testing (i.e. Sinkhole Repair or sinkhole mitigation). Sinkhole repair sites include the US 27 Polk (2010), US 27 Lake (2008), and Deland 15A (2016), in which CPTs were performed to assess the expanse of raveling zone around the perimeter of a recently formed sinkhole.

The Wekiva Parkway (2014) data was the only site in which no actual sinkhole collapse had occurred. Rather, CPTs were performed at this site to assess mitigation techniques in response to extremely loose material encountered above the limestone interface. Twentytwo SPTs were also performed at the Wekiva Parkway site. These tests not only show strong correlation in

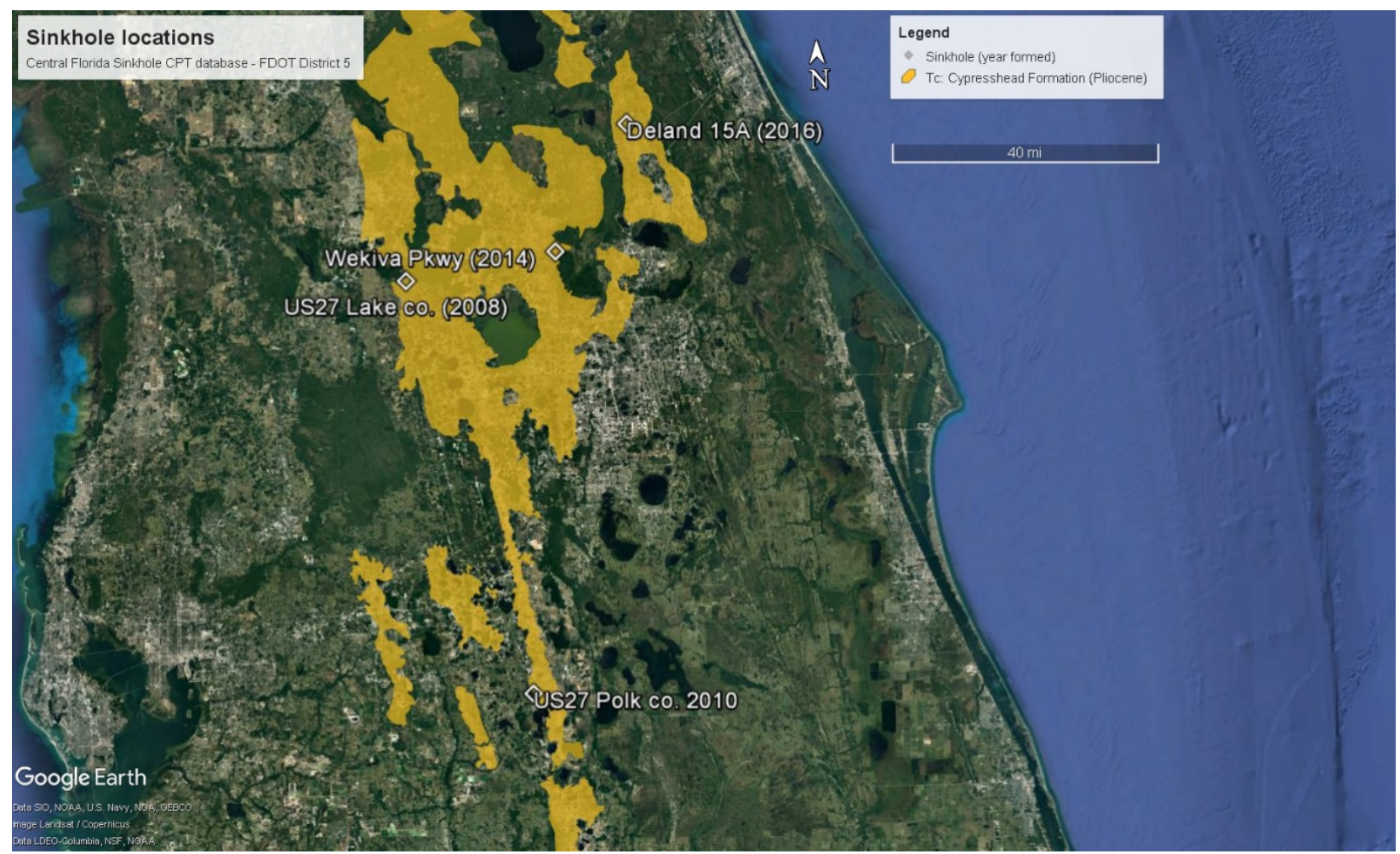

Figure 3. Location of Central Florida CPT data sites, located within the Cypresshead Formation (TC). 
encountered soil strata by comparing tip resistance trends in the CPTs, and blow count values from the SPT, but they also aid in the detection practice of raveled soils. Soil exhibiting extremely low tip resistant values may not always be a result of internal erosion. Research in soil classification using CPTs, shows that some naturally formed clays, highly organic silts, and colloidal fine-grained soils, may exhibit an abnormally low tip resistance value of less than $10 \mathrm{~kg} / \mathrm{cm}^{2}$ (Robertson, 1990). By retrieving soil samples from these layers of low tip resistance (possible with SPTs), it is much easier to determine whether the encountered soil is consistent with the expected soil strata in suspicion to be experiencing raveling. Figure 4 shows results from a CPT and an SPT, performed within close proximity to each other, at the Wekiva Parkway site. From the comparison, we see a strong correlation between the SPT blow count data (N60) and the Normalized tip resistance curve $\left(\mathrm{Q}_{\mathrm{tn}}\right)$. However, also apparent is the lack of resolution within the N60 curve due to the smaller sampling rate with depth from the SPT. Because of this limitation, SPTs were only used in this study to verify the type of soil encountered in the CPTs.

A total of 125 CPTs from the database sites were deemed significant for use in this study. The CPTs were categorized into three categories based on the encountered soils: Verified Raveled, Suspected Raveled, and non-raveled. The verified raveled CPTs were all taken from the three sinkhole collapse sites. Since there has recently been a collapse of a sinkhole within a few meters of the test, the loose material consistently encountered at depths above the limestone interface, were assumed to be associated with the nearby sinkhole collapse. The suspected raveled data set was obtained from CPTs at the Wekiva parkway project, where multiple SPTs and ground penetrating radar analysis suggests the possibility of internal erosion and sinkhole activity within the site property (PSI, 2014). However, also at the Wekiva parkway site, multiple CPTs did not encounter any anomalous soil. These CPTs were categorized as "non-raveled," due to the lack of indication of significant zones of loose material.

Although the CPTs were all performed within the same geological formation, raveled soils were encountered at varying depths, even within the same project site. Therefore, a normalization procedure was performed prior to filtering and comparison of the complete dataset. The normalization equation used in this study manipulates the measured tip resistance $\left(\mathrm{q}_{\mathrm{c}}\right)$ to produce a normalized, dimensionless, tip resistance $\left(\mathrm{Q}_{\mathrm{tn}}\right)$, as shown in Equation 1, and outlined in further detail by Robertson and Wride (1998).

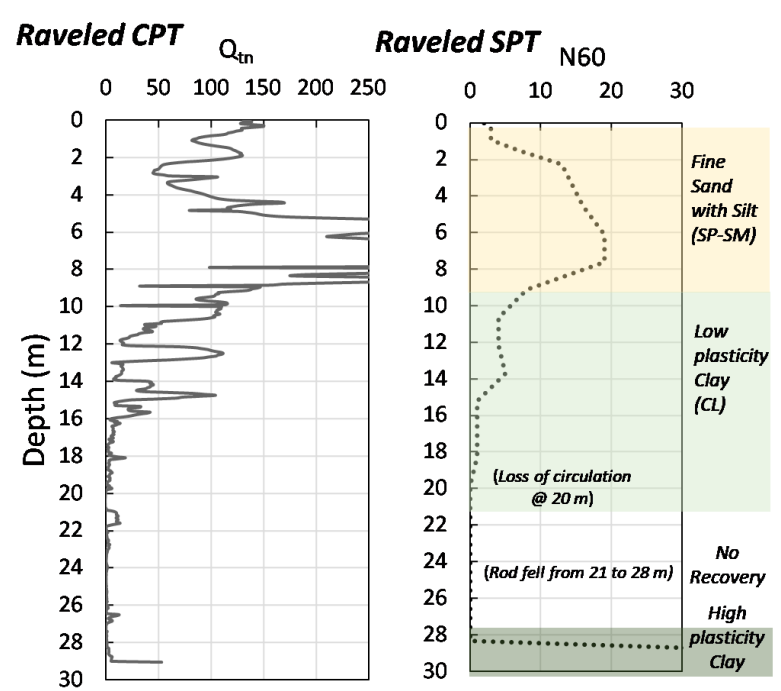

Figure 4. Comparison between a CPT tip resistance profile, and SPT blow count profile with stratified classification.

$$
Q_{t n}=\frac{q_{c}-\sigma_{v o}}{P_{a}} *\left(\frac{P_{a}}{\sigma_{v o}^{\prime}}\right)^{n} \quad \text { Eq. } 1
$$

where, $\mathrm{P}_{\mathrm{a}}$ is the atmospheric pressure; $\boldsymbol{\sigma}_{\boldsymbol{v o o}}$ and $\boldsymbol{\sigma}^{\prime}{ }_{\boldsymbol{v o}}$ is the estimated total and effective insitu vertical stress, respectively; and $n$ is the stress exponent, varying from 0.5 in sands, and 1.0 in clays (Olsen and Malone, 1988). An assumed value of 0.65 was used for the stress exponent in all cases. Likewise, the effective stresses were calculated based on an assumed soil unit weight of $17.3 \mathrm{kN} / \mathrm{m}^{3}$ for each test, with the groundwater table depths taken from SPT observations for each site. It should be noted that the measured sleeve friction value $\left(f_{s}\right)$ was not normalized or corrected for overburden stresses. Normalization of $\mathrm{f}_{\mathrm{s}}$ is a highly debated topic and is not well established in literature. The resulting data set, after normalization, consists of $\mathrm{Q}_{\mathrm{tn}}$ values and the respective $\mathrm{f}_{\mathrm{s}}$ values, at each measuring depth (every $2 \mathrm{~cm}$ ). The average depth of CPT analyzed in this study was 33 meters, therefore the data set from all 125 tests was immense and needed to be filtered for proper analysis.

\section{Data filtering}

The following filtering procedure was performed on the $\mathrm{Q}_{\mathrm{tn}}$ data from the CPTs in the verified and suspected raveling group. Each respective $f_{s}$ was also then deleted from the data set. This was performed in two primary steps and an example of such is shown in Figure 5. The goal of this step is to create a new dataset with CPT parameters strictly from raveled soils. 


\section{Raveled CPT $\mathrm{Q}_{\mathrm{tn}}$}

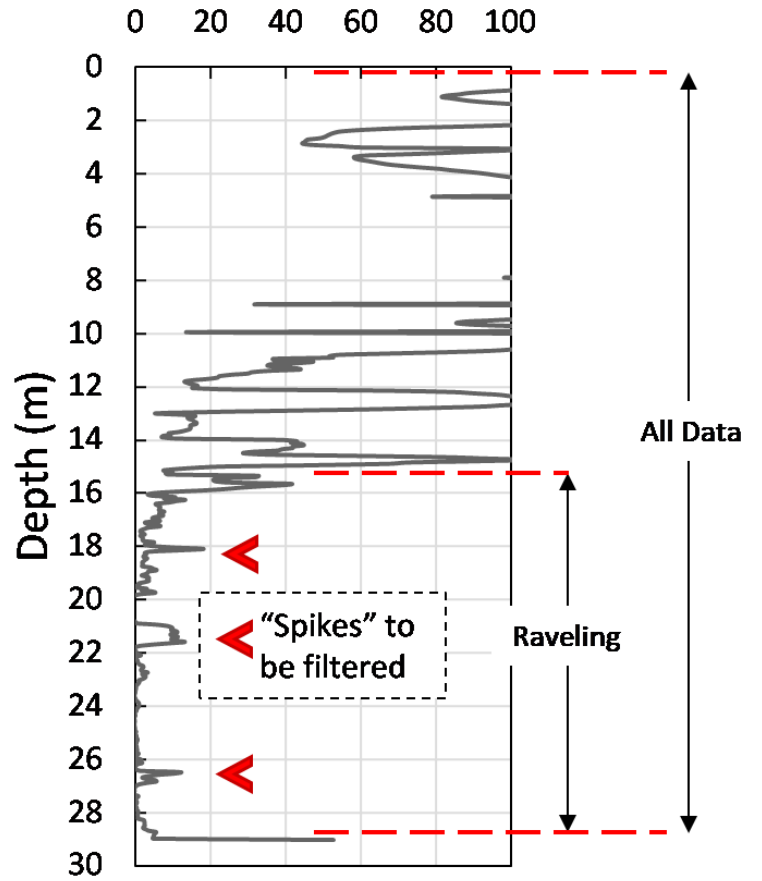

Figure 5. Example of filtering procedure to identify data within raveled zone only.

1). In the CPTs performed within proximity to SPT borings suggesting raveling conditions, an expected depth-of-raveled was established and only data within that window was kept. Figure 4 shows a prime example of how SPT results - such as weight of hammer/rod conditions, or loss of drilling circulation - can be used to estimate the depths at which raveling starts. Further details on this technique can be found in Gray and Bixler's paper (1994) regarding detection practices of sinkholes in Central Florida using the SPT. For CPTs performed without any nearby SPT borings, the raveled soil zone was assumed to be the abnormally low $\mathrm{q}_{\mathrm{c}}$ values directly above the refusal layer. Luckily, the only project site analyzed which did not have SPTs performed, was a site where a collapsed sinkhole had formed. Therefore, the assumption that the encountered loose soils is a sign of sinkhole activity, is validated by nearby collapsed sinkhole.

2) Once the data from the raveled soil zone was determined, further filtering was performed to account for the non-homogenous soil. Even in the raveled soil zones, the penetrating cone sensor may push into lenses of harder material, such as weathered limestone fragments, shell, or phosphates. Since the penetrating cone sensor is roughly $3.54 \mathrm{~cm}$ in diameter, the slightest inconsistency in material density can skew the $\mathrm{Q}_{\mathrm{tm}}$ curve, causing a drastic "spike". Although these lenses of material most likely will affect the over-all severity of the raveled zone in regards to its possible collapse (Shamet 2017), the purpose of this study is to identify how CPTs record values of $Q_{t n}$ and $f_{s}$ data in the raveled material. Therefore, these "spikes" are excluded from the analyzed data set.

\section{Data Analysis}

The effects of filtering the data is apparent by simply viewing the data sets on a scatter plot, as shown in Figure 6 . In both the collapse site data, and the suspectedraveled site data, we see a drastic decrease in large $Q_{t n}$ values during the filtering process; however, the range of $\mathrm{f}_{\mathrm{s}}$ seems to show less deviation.

Another observation from Figure 6 is the concentrated group of negative $f_{s}$ values in the suspected raveling data set. This anomaly was measured at similar depths from several CPTs performed close to each other. Therefore, the negative sleeve friction is most likely a result of an isolated instance of either improper calibration. Regardless, this encountered negative sleeve friction requires further investigation and is beyond the scope of this paper, therefore is also excluded from the data set.

The filtered data from both the suspected and raveled sites show similar trends in mean, average, and upper limits for both $\mathrm{Q}_{\mathrm{t}}$ and $\mathrm{f}_{\mathrm{s}}$. Therefore, for the purpose of developing the raveling chart, both data sets will be included as one to increase in the sample size.

\section{Raveling}

The combined CPT-raveled data set now consists of a total of 7334 data points (i.e $Q_{t \mathrm{t}}, f_{\mathrm{s}}$ ). When mapped on a scatter plot, there is an apparent confinement of the raveled data. Based strictly on visual observation, the majority of the data seems to fall within the values of $0-26$ for $Q_{t m}$, and $0-1.0 \mathrm{~kg} / \mathrm{cm}^{2}$ for $\mathrm{f}_{\mathrm{s}}$. However, the relationship between minimum $\mathrm{Q}_{\mathrm{tn}}$ and maximum $\mathrm{f}_{\mathrm{s}}$ is not as easy to define. As shown in Figure 6, the CPT-raveled data cluster loses its density as $f_{s}$ increases. In order to properly define this boundary of data containment, a moving histogram analysis was conducted for $f_{s}$ in terms of its $Q_{t n}$ bin. The values of $\mathrm{Q}_{\mathrm{tn}}$ were ranked in numerical order, and separated into 19 bins of equal sample size. Since there is a total 7334 data points, each bin consisted of 386 data points (i.e. $7334 / 19=386$ ). The mean, quartiles, and inter-quartile ranges were then calculated for the $f_{s}$ data in each respective $Q_{t \mathrm{t}}$-bin. Figure 7 shows the results of such statistical analysis. The ' $+1.5 * \mathrm{IQR}$ ' data points were calculated by determining the interquartile range (IQR) for the $\mathrm{f}_{\mathrm{s}}$ values in each $\mathrm{Q}_{\mathrm{tn}}$ bin. By multiplying 

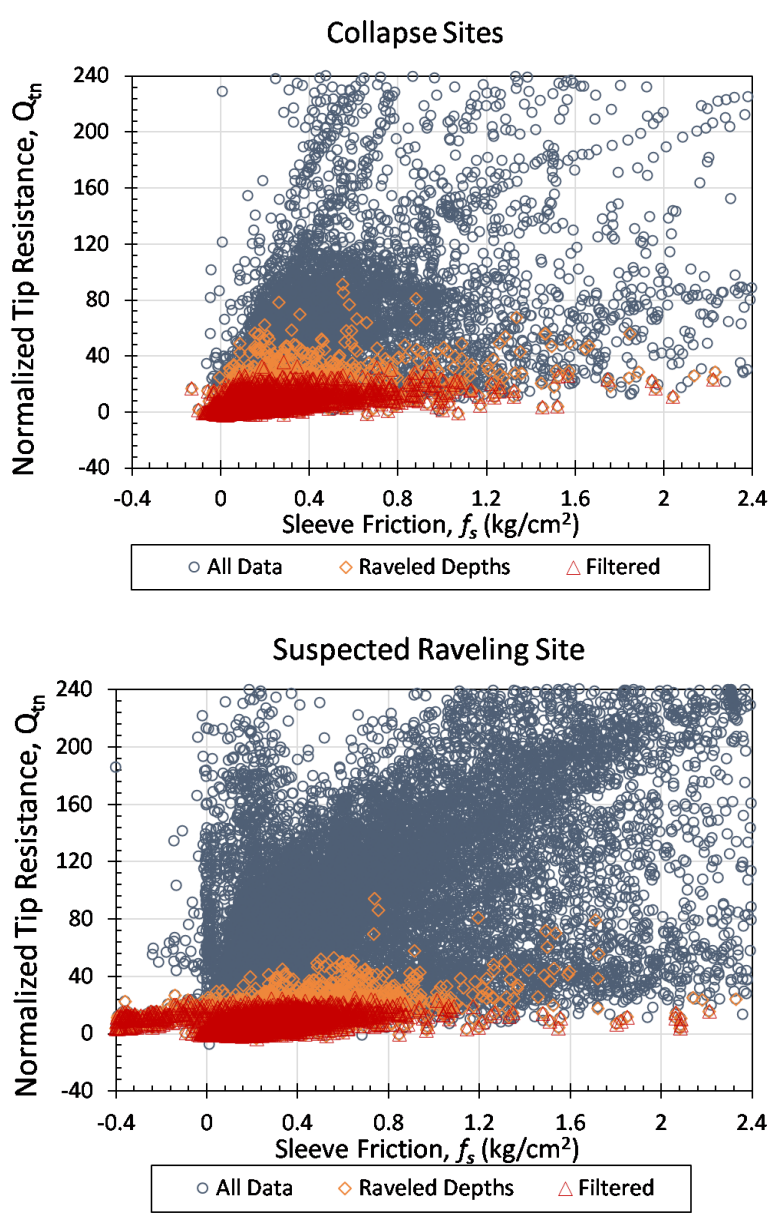

Figure 6. Comparison of data from suspected raveling and collapsed sites, at each stage of the filtering process.

the IQR by 1.5 and adding it to the third quartile value, we get a data point representing the upper "whisker" for that specific bin data.

The upper "whisker" data point represents the value of $f_{s}$ which is greater than approximately $98 \%$ of the remaining $f_{s}$ in that bin. Therefore, we can use this value as a conservative maximum, stating that any $f_{s}$ encountered less than this value, for a specific range of $Q_{t \mathrm{t}}$, will be representative of raveled soils. When we perform this analysis for each bin of $\mathrm{Q}_{\mathrm{t}}$ values, a clear trend is observed in the resulting means and upper interquartile range "whiskers" (1.5*IQR). The envelope drawn by power-law regression of the upper "whiskers" in $f_{s}$ data, will be used as the upper envelope of $f_{s}$ and lower envelope of $\mathrm{Q}_{\mathrm{tn}}$ within the CPT-raveled data set.

\section{Non-Raveling}

Similar data analysis was performed for the CPT database of non-raveled material-obtained from

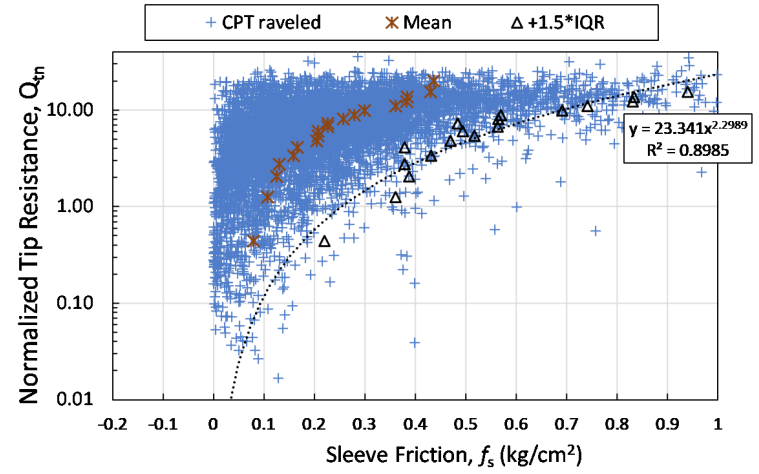

Figure 7.

CPT-raveled data scatter with upper-bound $f_{s}$ quartile envelope.

the Wekiva parkway site. However, no filtering was performed on this dataset since there was no clear trend in $Q_{t n}$ data profiles, suggesting raveling. Therefore, the resulting data ranges were much larger, as expected, than the Raveling Data set. The final non-raveled data group consisted of a total of 4244 data sets. Therefore, to keep consist with the Raveling analysis, a total of $12 \mathrm{Q}_{\mathrm{tm}}$ bins were used to assess the $\mathrm{f}_{\mathrm{s}}$ histogram plots (resulting in 362 data points in each bin).

Figure 8 presents the results of the same mean and upper "whisker" calculation, expect for the CPT-non raveled data set. However, there is a clear discrepancy in data's mean values of $f_{s}$ as the $Q_{t n}$ bins increase. This clear jump in data suggests the upper and lower ranges of $Q_{t n}$ (shown boxed in Figure 8) may be obtained from different data sets. Recall that this specific analyzed CPT-non-raveled data set did not have any filtering procedure applied to it. Even though the CPT profile curves of $\mathrm{Q}_{\mathrm{tn}}$, within this data set, did not suggest raveled soil was encountered, smaller zones of loose material (low $\mathrm{Q}_{\mathrm{tn}}$ ) were still encountered in many of the tests.

These relatively smaller zones of soft soils may still indicate soil internal erosion, but on a less severe scale as the ones in the raveled data set. Therefore, this "transition" of raveled-to-non-raveled soil data is still of significance and will be incorporated into the soilraveling chart. Since the verified raveled soil range of $Q_{\mathrm{tm}}$ appeared to have a maximum value of 26 , the transitional range of raveled soil conservatively includes values of $\mathrm{Q}_{\mathrm{tn}}$ up to 50. The upper $\mathrm{f}_{\mathrm{s}}$ envelope within this $\mathrm{Q}_{\mathrm{tn}}$ range was also calculated using the same technique as for the raveled data set. However, the upper "whiskers" of $f_{s}$ in this specific range, follow more closely linear trend, rather than to a power law. 


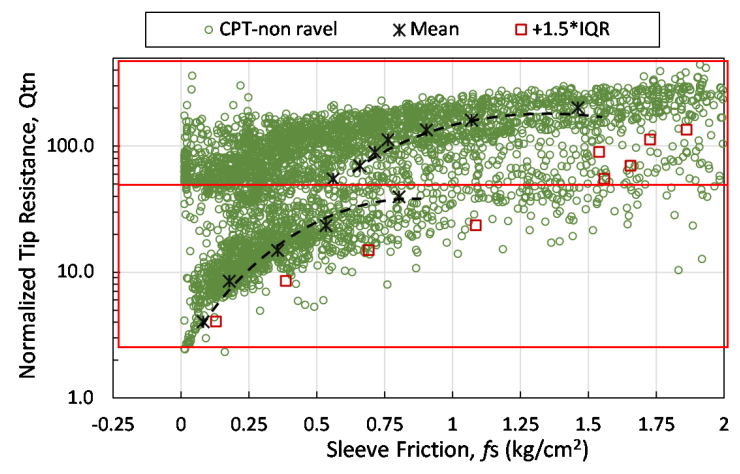

Figure 8. CPT-non-raveled data scatter with split in upper-bound mean envelopes.

\section{CPT-Based Raveling Chart}

The comparison of raveled and non-raveled CPT data sets, presented in the earlier sections, were used to develop a CPT-based raveled chart for central Florida sites existing within the Cypress head formation of residual soils. This chart, presented in Figure 9, was developed as a tool to identify potential raveled soils from $\mathrm{Q}_{\mathrm{tn}}$ and $\mathrm{f}_{\mathrm{s}}$ values obtained from CPTs. Practitioners can quickly plot the CPT parameters along this chart, to estimate the likely hood of sinkhole forming raveled soils, during initial site investigation. The five categories which make up the chart represent the most likely degree of raveling encountered within the soil. The boundary lines were created using the aforementioned analysis on both the raveled and non-raveled data sets and are summarized in Table 1. During initial site investigation, if a CPT performed results in a large amount of data falling within the "Raveled soil" category, then the data greatly coincides with CPT stiffness parameters measured from soil which has experienced internal erosion. The Raveled soil* category was included as a provisional or transitional stage. If data from a CPT falls within this zone, but not within the "raveled soil" category, then this soil is most likely undisturbed or at least has not experienced a great amount of raveling yet. The categories labeled "Out of Range" are such that conclusive results could not be drawn strictly from the lack of data within those ranges. However, due to the few isolated occurrences of $\mathrm{f}_{\mathrm{s}}<0$, any data falling in this zone will most likely have a correlation to sinkhole activity, but further investigation should be performed to verify this conclusion.

\section{Summary and Conclusion}

The information presented in this study provides an extensive look at the results of Cone penetration testing performed at sites associated with sinkhole activity. A CPT database was developed from a total of 3 historical sinkhole collapse sites located in Central Florida. This

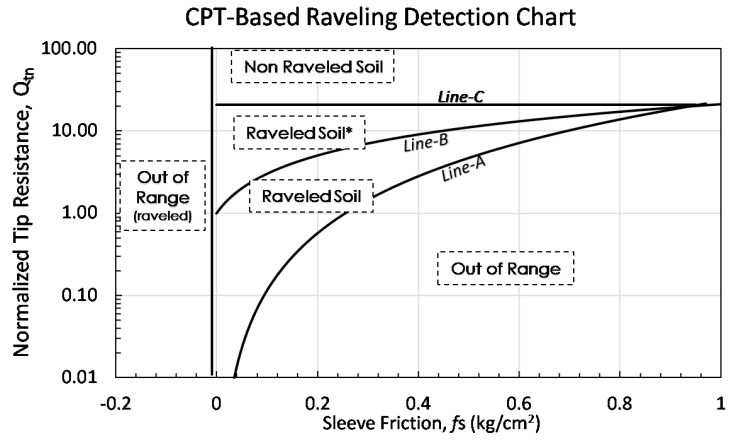

Figure 9. Proposed raveling chart using CPT data $\left(Q_{t n}\right.$ vs. $\left.f_{s}\right)$ for Central Florida

\begin{tabular}{|c|c|} 
Line & Equation \\
\hline A & $Q_{t n}=23.241\left(f_{s}\right)^{2.2989}$ \\
\hline$B$ & $Q_{t n}=25.5 * f_{s}+1.0039$ \\
\hline$C$ & $Q_{t n}=26$ \\
\hline
\end{tabular}

Table 1. Category envelope equations for CPT raveling Chart

database was compared to another database of CPT data from a site which had no sinkhole collapse in recent history, but showed strong suggestion that sinkhole activity may be occurring unseen. After comparing and deeming the two datasets statistically comparable, they were combined and analyzed to obtain the limiting values of $Q_{t n}$ and $f_{s}$ which indicate sinkhole raveling. Additionally, a third dataset was collected and formed of tests which showed no signs of sinkhole forming-soil raveling. This data group was also analyzed using the same technique, and value boundaries were also set. The resulting analysis between the two groups (raveled vs non-raveled) showed a clear distinction between the two's typical $\mathrm{Q}_{\mathrm{tn}}$ and $\mathrm{f}_{\mathrm{s}}$ data, but also showed a zone of data overlap. The resulting envelopes were used to create the proposed raveling chart shown in figure 9. This chart can be implemented to aid in the risk evaluation future sinkhole development during the initial site characterization through correlating any loose soils at a potential sinkhole site, with those obtained from a site with known sinkhole activity. If a large portion of CPT data lies within the "raveled soil" area on the chart, then engineers can conclude that the encountered soil has most likely been exposed to a type of internal erosion indicative of sinkhole formation. Caution should be used, however, when implementing this chart with CPTs data obtained from areas not lying within Cypresshead formation of soils; or at least within sediments of 
similar geological deposition. Current studies are being performed to verify the proposed chart is consistent for other geological group soils associated with karst sinkhole formation in Florida. However, the authors believe this proposed chart will still aid engineers through "adding another tool to the toolbox" when discerning whether further subsurface investigation are necessary or to aid in selection of mitigation technique.

\section{Acknowledgement}

The authors thank the supports from Florida Department of Transportation (FDOT). The opinions expressed in this paper are those of the researchers and do not necessarily represent those of the sponsors.

\section{References}

ASTM Standard D5778. 2012. Standard Test Method for Electronic Friction Cone and Piezocone Penetration Testing of Soils. West Conshocken, PA. ASTM International

Beck B, Sinclair W. 1986. Sinkholes in Florida. Orlando. The Florida Sinkhole Research Institute

FGS. 2001. Text to accompany the Geologic Map of Florida. Tallahassee. Florida Geological Survey.

Gray K, Bixler B. 1994. Cover Subsidence sinkhole evaluation of state road 434, Longwood Florida. ASCE Journal of Geotechnical Engineering 20262040.

Jammal J. 1984. A self-guided field trip to the Winter Park Sinkhole. Orlando. The Florida Sinkhole Research Institute

Meyerhof GG. 1956. Penetration Tests and bearing Capacity of cohesionless soils. Soil Mechanics Foundation-Division. American Society of Civil Engineers

Olsen RS, Malone PG. 1988. Soil Classification and site characterization using the cone penetrometer test. Penetration Testing. Procedings of the 1st International Symposium on Penetration Testing, ISOPT-1, Orlando, 20-24 March 1, V2, AA Balkema, Rotterdam, p. 887-893

Professional Services Inc. Report. 2014. Sinkhole and Engineering evaluation: Wekiva Parkway and State Road 46 Connector Road Interchange. Orlando. Florida Department of Transportation.

Robertson PK. 1990. Soil Classification using the Cone Penetrometer test. Canadian Geotechnical Journal, 27: $151-158$

Robertson PK, Wride CE. 1998. Evaluating cyclic liquefaction potential using the cone penetration test. Canada. Geotech 442-459

Schmertmann, JH. 1978. Guidelines for Cone Penetration Tests, Performance and Design.
Washington. Federal Highway Administration, FHWA-TS-78-209.

Shamet R, Perez A, Nam BH. 2017. Sinkhole Risk Evaluation: Detection of Raveled soils in Central Florida's Karst Geology Using CPT. In: Huang J, Fenton GA, Zhanag L, Griffiths DV, editors, Geo-Risk 2017: Impact of Spatial Variability, Probabilistic Site Characterization, and Geohazards. American Society of Civil Engineers, Georisk Conference. p. 257-266

Tihansky, AB. 1999. Sinkholes, West-Central Florida. In Galloway D. Jones DR, Ingebritsen SE. Land Subsidence in the United States: USGS Circular 1182, p. 121-140. 